\title{
High-Precision Sr-Nd-Hf-Pb Isotopic Composition of CGSG-1, CGSG-2, CGSG-4 and CGSG-5 Reference Materials by MC-ICP-MS and TIMS
}

Y.H. YANG ${ }^{1 *}$ M. YANG ${ }^{1}$, K.P. JOCHUM ${ }^{2}$, S.T. WU ${ }^{1}$, H. ZHAN $^{1}$, L.W. XIE ${ }^{1}$, C. HUANG ${ }^{1}$, X.C. ZHAN ${ }^{3}$, J.H. YANG $^{1}$ AND F.Y. WU ${ }^{1}$

${ }^{1}$ State Key Laboratory of Lithospheric Evolution, Institute of Geology and Geophysics, Chinese Academy of Sciences, Beijing 100029, P. R. China (*correspondence: yangyueheng@mail.iggcas.ac.cn)

${ }^{2}$ Cimate Geochemistry Department, Max Planck Institute for Chemistry, P.O.B. 3060, D-55020 Mainz, Germany

${ }^{3}$ National Research Center for Geoanalysis, Beijing, 100037 , P. R. China

Glass reference materials play an important role in microanalysis, using techniques like EPMA, LA-(MC)-ICPMS, and SIMS. They are usually used as known or unknown samples for external calibration, method development, quality control and inter-laboratory comparison. For example, NIST SRM glasses, the various USGS glass materials and MPIDING are widely used as micro-analytical reference materials.

The widespread distribution and usage glass reference materials, not only because of their major and trace elements, but also their isotopic characterizations, make them significant reference materials for microanalysis. Because of widely distributed NIST, USGS and MPI-DING series glasses, there are also various publications focused on their isotopic compositions.

To assess the homogeneity and provide first $\mathrm{Sr}-\mathrm{Nd}-\mathrm{Hf}-\mathrm{Pb}$ isotopic reference values of the Chinese Geological Standard Glasses CGSG-1, CGSG-2, CGSG-4 and CGSG-5, we analyzed the $\mathrm{Sr}-\mathrm{Nd}-\mathrm{Hf}-\mathrm{Pb}$ isotopic compositions of CGSG glasses at several analytical sessions over the course of nealy three years. The results were obtained by high-precision MCICP-MS and TIMS. Our investigation indicates that these CGSG glass reference materials are homogenous regards to $\mathrm{Sr}-\mathrm{Nd}-\mathrm{Hf}-\mathrm{Pb}$ isotopic distribution and are therefore suitable geochemical materials for $\mathrm{Sr}-\mathrm{Nd}-\mathrm{Hf}-\mathrm{Pb}$ isotope measurements. Obvious difference of $\mathrm{Sr}-\mathrm{Nd}-\mathrm{Hf}-\mathrm{Pb}$ isotopic composition was observed between the glasses and the original powdered rock reference materials (CGSG-2 and GSR-7, especially CGSG-5 and GSR-2) because of flux addition during the glass preparation. The new $\mathrm{Sr}-\mathrm{Nd}-\mathrm{Hf}-\mathrm{Pb}$ isotope data provided here might be useful in the geochemical community for in situ and bulk analysis. 